\title{
Keystone Flap with Omega Variation and Sydney Melanoma Unit Modification to Cover Small- and Moderate-Sized Defects in the Anterior Lower Leg
}

\author{
Yu Taek Kong* (D), Junekyu Kim* (D), Hyun Woo Shin (D), Kyu Nam Kim (D) \\ Department of Plastic and Reconstructive Surgery, Kangbuk Samsung Hospital, Sungkyunkwan University School of Medicine, Seoul, Korea
}

\begin{abstract}
Background: Covering a small defect on the anterior lower leg is challenging because less soft tissue is available. This study presents the application of a keystone flap (KF) with omega variation (OV) and Sydney melanoma unit modification (SMUM) for small- and moderatesized pretibial defects.

Methods: This study included a series of six cases of anterior lower leg defect reconstruction with OV and SMUM KF technique by a single surgeon between December 2017 and June 2020. Records and photographs of the patients were collected and analyzed.

Results: The defects' sizes ranged from $1.5 \times 2.5$ to $6 \times 8 \mathrm{~cm}$. All defects were covered with OV KF, SMUM KF, or OV SMUM KF based on the hotspots of surrounding perforators. The flap sizes varied from $3 \times 6$ to $8 \times 17 \mathrm{~cm}$. Moreover, all flaps were completely viable. A marginal maceration developed in one case, which was mended with conservative dressing. Outcomes were favorable in all patients during the average follow-up period of $4.83 \pm 1.17$ months.

Conclusion: This study successfully covered small- and moderate-sized anterior lower leg defects with OV and SMUM KF. We therefore suggest the OV and SMUM KF techniques as good alternative modalities for anterior lower leg reconstruction.
\end{abstract}

Keywords: Lower extremity; Perforator flap; Wound

\section{Introduction}

The coverage of defects in the anterior lower leg is often challenging and difficult for reconstructive surgeons because of relatively insufficient soft tissue compared to other areas of the lower leg [1,2]. This inherent feature of the anterior lower leg makes the coverage of even a small defect difficult, resulting in the exposure of underlying structures (e.g., tendons and bones) [1,2]. Today, free-flap surgery is a valuable reconstructive tool for covering defects in the lower extremities, given recent advancements in microsurgical concepts and skills [2,3]. However, free-flap surgery requires several conditions, including skilled microsurgeons, the hospital's capacity to support microsurgical operation and care, and the patient's ability to bear microsurgery [2,4-6]. This means that other reconstructive modalities (e.g., skin grafting and local flaps) are still useful in lower extremity reconstruction. Particularly, local flaps can be the primary choice for coverage in some cases and are applicable as an alternative to free tissue transfers in lower extremity reconstruction [2,5]. This study presents the experience of using the keystone flap (KF) with omega variation (OV) [7] and Sydney melanoma unit modification (SMUM) [8] for covering small- to moderate-sized defects in the anterior lower leg. The main purpose of the present study is to substantiate the practical and versatile application of OV and SMUM KF in lower extremity reconstruction.
Original Article

Received: December 16, 2020

Revised: March 5, 2021

Accepted: March 8, 2021

\section{Corresponding author:}

Kyu Nam Kim, M.D., Ph.D.

Department of Plastic and Reconstructive Surgery, Kangbuk Samsung Hospital,

Sungkyunkwan University School of Medicine,

29 Saemunan-ro, Jongno-gu, Seoul 03181,

Korea

Tel: +82-2-2001-2182

Fax: +82-2-2001-2117

E-mail: manabear77@naver.com

*These authors contributed equally to this work.

This article was presented as an e-poster at PRS KOREA 2020 on November 13-15, 2020.

This is an Open Access article distributed under the terms of the Creative Commons Attribution Non-Commercial License (https://creativecommons org/licenses/by-nc/4 O/) which permits unrestricted non-commercial use, distribution, and reproduction in any medium, provided the original work is properly cited.

(c) 2021 Korean Wound Management Society 


\section{Methods}

The study involved patients who underwent KF reconstruction with OV and SMUM to cover defects in the anterior lower leg from December 2017 to June 2020. Patients who underwent only KF reconstruction, i.e. only the OV KF, only the SMUM KF, and a combination of the OV and SMUM KF, were included. However, patients who underwent anterior lower leg reconstruction using other types of KF, such as type I (skin incision only), type II (a division of the deep fascia), type III (opposing KFs designed to create a double-KF), and type IV (KF with undermining of up to $50 \%$ of the subfascial flap) [9] were excluded. Data from the patients' medical records and clinical photographs, including cause of defect, defect location, defect size, flap size, KF type, flap survival, postoperative complications, and follow-up period, were retrospectively reviewed and evaluated.

This study was approved by the Institutional Review Board of Konyang University Hospital (approval number: 2017-07004). Moreover, all research procedures in this study were performed following the ethical guidelines of the 1975 Declaration of Helsinki. All participants provided written informed consent.

\section{Surgical techniques}

Each patient received preoperative management for wound preparation, including serial debridement, conventional wound dressing, negative-pressure wound therapy, and antibiotic treatment to control infection and inflammation of surrounding tissues, for at least 1-2 weeks. The final defect was covered with the KF technique with OV and SMUM after achieving wound preparation and stabilization through these treatments. The operation was performed in the supine position and under local or general anesthesia, depending on the size of the defect and the patient's general condition. The final defect was measured after complete debridement. Consequently, we tried to check and mark perforator hotspots around the defect using a handheld ultrasound Doppler device as much as possible, especially in larger defects. Both the size of the defect and laxity of surrounding tissue were considered when designing the flap $[2,5,6]$. The width of the flap was designed to be larger than that of the defect, and the flap center was located on the marked perforator hotspots $[2,5,6]$.

Either OV KF alone, SMUM KF alone, or a combination of OV and SMUM KF was used for each case. OV KF was used to add rotational flap movement. The original defect was therefore closed in a fish mouth fashion [5-7]. SMUM KF involves the maintenance of a skin bridge along the greater $\mathrm{KF}$ arch $[5,6,8]$. Basically, we used the SMUM KF in case of either smaller defects or imprecise perforator hotspots found in Doppler tracing, and used the OV KF when there was need for further flap movement to achieve tensionless closure. The modification was decided intraoperatively instead of preoperatively; specifically, the initial skin incisions were performed with the maintenance of a skin bridge along the greater KF arch (SMUM), and then could be converted into OV (extension of incision through the skin bridge) according to intraoperative findings. Fig. 1 illustrates OV KF and SMUM KF. A skin incision was created along the flap, and dissection was done from the subcutaneous layer to the deep fascia. A skin bridge along the greater arch of the KF remained when SMUM KF was applied. Minimal undermining of the flap margin was performed to preserve vascular perfusion of the central perforator hotspot $[2,5,6]$. This procedure should only be done to the extent that the flap is moved toward the defect in either linear or OV closure with minimum tension. After meticulous hemostasis, the flap was inserted in the following sequence: first, the defect side of the flap was sutured in either linear or OV closure, followed by both ends of the flap in a $\mathrm{V}-\mathrm{Y}$ closure fashion; second, the donor site of the flap was sutured; and lastly, a mild compressive dressing with foam materials was applied.

\section{Postoperative scar management}

This study recommended that the patients use CICA-CARE (Smith \& Nephew, Watford, UK), a silicone gel sheeting designed for postoperative scar management, for 2-3 months postoperatively.

\section{Results}

The study included six patients (four men and two women) with an average age of $41.67 \pm 22.42$ years (range, $14-70$ years). Table 1 summarizes the patients' characteristics and clinical data. The defects' etiology included skin necrosis due to trauma in five patients, and skin necrosis from burns in one patient. The defects' locations included the lower third of the anterior lower leg, the middle third, and the upper third in two, three, and one patient, respectively. The defect and flap sizes ranged from $1.5 \times 2.5$ to $6 \times 8 \mathrm{~cm}$ and $3 \times 6$ to $8 \times 17 \mathrm{~cm}$, respectively. Using handheld ultrasound Doppler tracing intraoperatively, precise perforators were obtained for two patients. Four 

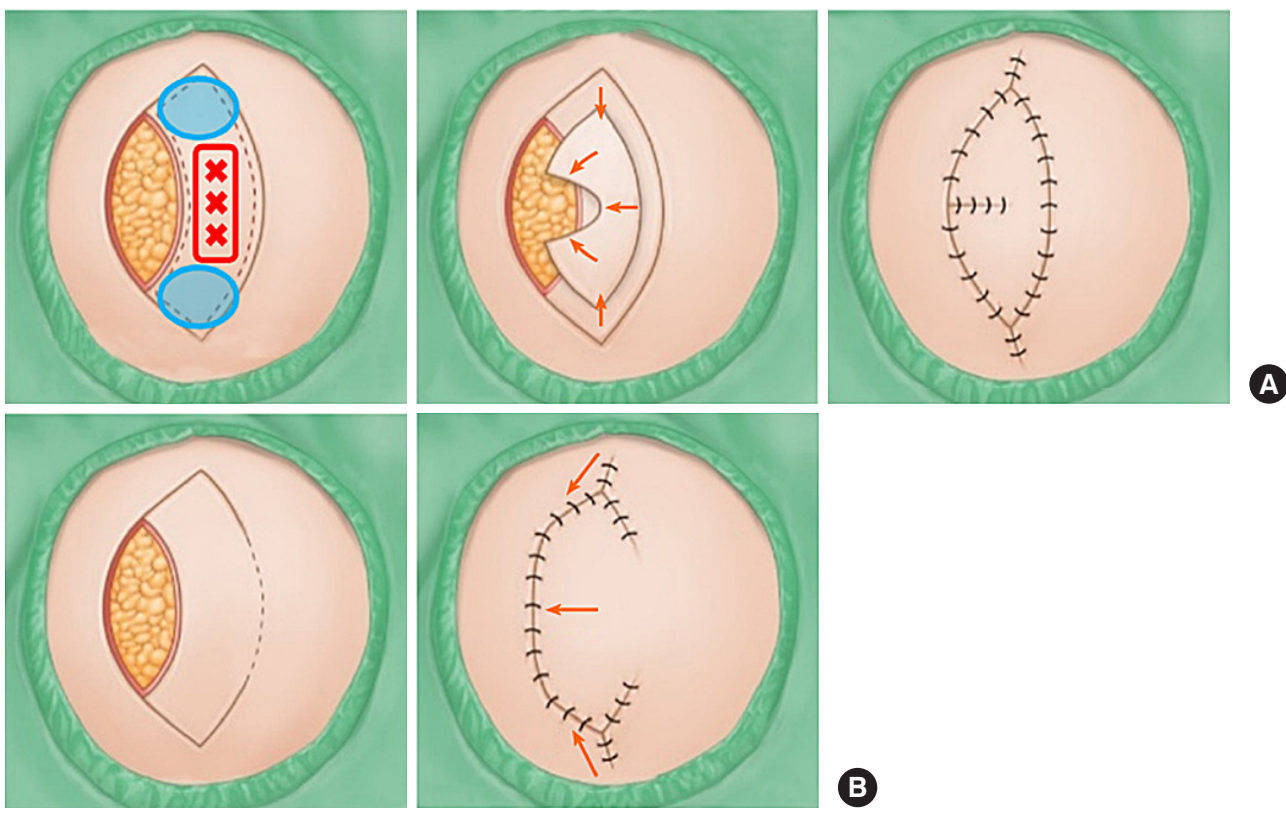

Fig. 1. Schematic illustration of OV and SMUM. (A) OV keystone flap. Further undermining of the flap (blue circles) with preserving the central hot spot of perforators (red $x$ marks). (B) SMUM keystone flap (maintenance of a skin bridge along the greater arc of the keystone design perforator island flap). Red arrows indicate directions of the flap movement. OV, omega variation; SMUM, Sydney melanoma unit modification. Reprinted from Lim et al. World J Clin Cases 2020;8:1832-47 [6].

Table 1. Patients data

\begin{tabular}{|c|c|c|c|c|c|c|c|c|c|c|c|}
\hline Case & $\begin{array}{l}\text { Sex/age } \\
\text { (yr) }\end{array}$ & Defect cause & $\begin{array}{l}\text { Defect } \\
\text { location }\end{array}$ & $\begin{array}{c}\text { Defect } \\
\text { size }(\mathrm{cm})\end{array}$ & $\begin{array}{l}\text { Flap size } \\
\text { (cm) }\end{array}$ & $\begin{array}{c}\text { Intraoperative } \\
\text { handheld ultrasound } \\
\text { Doppler tracing }\end{array}$ & KF type & Anesthesia & $\begin{array}{l}\text { Flap } \\
\text { survival }\end{array}$ & Complications & $\begin{array}{l}\text { Follow-up } \\
\text { period } \\
\text { (mon) }\end{array}$ \\
\hline 1 & $\mathrm{M} / 70$ & $\begin{array}{l}\text { Skin necrosis } \\
\text { due to trauma }\end{array}$ & $\begin{array}{l}\text { Lower } 1 / 3 \text { of left } \\
\text { anterior lower } \\
\text { leg }\end{array}$ & $1.8 \times 4$ & $3.5 \times 7.5$ & $\begin{array}{l}\text { Imprecise } \\
\text { perforator mapping }\end{array}$ & SMUM KF & $L A$ & $\begin{array}{l}\text { Fully } \\
\text { survived }\end{array}$ & None & 5 \\
\hline 2 & $\mathrm{M} / 52$ & $\begin{array}{r}\text { Skin necrosis } \\
\text { due to burn }\end{array}$ & $\begin{array}{l}\text { Middle } 1 / 3 \text { of } \\
\text { right anterior } \\
\text { lower leg }\end{array}$ & $2 \times 3.5$ & $3.5 \times 7$ & $\begin{array}{l}\text { Imprecise } \\
\text { perforator mapping }\end{array}$ & $\begin{array}{l}\text { OV and } \\
\text { SMUM KF }\end{array}$ & $\mathrm{GA}$ & $\begin{array}{l}\text { Fully } \\
\text { survived }\end{array}$ & None & 4 \\
\hline 3 & $F / 28$ & $\begin{array}{l}\text { Skin necrosis } \\
\text { due to trauma }\end{array}$ & $\begin{array}{l}\text { Lower } 1 / 3 \text { of } \\
\text { right anterior } \\
\text { lower leg }\end{array}$ & $1.8 \times 3.5$ & $3.5 \times 8$ & $\begin{array}{l}\text { Imprecise } \\
\text { perforator mapping }\end{array}$ & $\begin{array}{l}\text { OV and } \\
\text { SMUM KF }\end{array}$ & $L A$ & $\begin{array}{l}\text { Fully } \\
\text { survived }\end{array}$ & None & 7 \\
\hline 4 & $M / 25$ & $\begin{array}{l}\text { Skin necrosis } \\
\text { due to trauma }\end{array}$ & $\begin{array}{l}\text { Middle } 1 / 3 \text { of left } \\
\text { anterior lower } \\
\text { leg }\end{array}$ & $1.5 \times 2.5$ & $3 \times 6$ & $\begin{array}{l}\text { Imprecise } \\
\text { perforator mapping }\end{array}$ & $\begin{array}{l}\text { OV and } \\
\text { SMUM KF }\end{array}$ & $L A$ & $\begin{array}{l}\text { Fully } \\
\text { survived }\end{array}$ & $\begin{array}{l}\text { Marginal } \\
\text { maceration }\end{array}$ & 4 \\
\hline 5 & $\mathrm{M} / 14$ & $\begin{array}{l}\text { Skin avulsion } \\
\text { due to trauma }\end{array}$ & $\begin{array}{l}\text { Upper } 1 / 3 \text { of left } \\
\text { anterior lower } \\
\text { leg }\end{array}$ & $3 \times 4$ & $5 \times 12$ & $\begin{array}{l}\text { Precise } \\
\text { perforator mapping }\end{array}$ & $\begin{array}{l}\text { OV and } \\
\text { SMUM KF }\end{array}$ & $\mathrm{GA}$ & $\begin{array}{l}\text { Fully } \\
\text { survived }\end{array}$ & None & 5 \\
\hline 6 & $F / 61$ & $\begin{array}{l}\text { Skin and soft } \\
\text { tissue defect } \\
\text { due to trauma }\end{array}$ & $\begin{array}{l}\text { Middle 1/3 of left } \\
\text { anterior lower } \\
\text { leg }\end{array}$ & $6 \times 8$ & $8 \times 17$ & $\begin{array}{l}\text { Precise } \\
\text { perforator mapping }\end{array}$ & $\begin{array}{l}\text { OV KF and } \\
\text { additional } \\
\text { skin graft }\end{array}$ & $\mathrm{GA}$ & $\begin{array}{l}\text { Fully } \\
\text { survived }\end{array}$ & None & 4 \\
\hline
\end{tabular}

KF, keystone flap; M, male; F, female; SMUM, Sydney melanoma unit modification; OV, omega variation; LA, local anesthesia; GA, general anesthesia.

defects were covered using OV and SMUM KF, one defect was covered using SMUM KF, and another defect was covered using OV KF combined with an additional tiny skin graft. All flaps remained completely viable without flap-related complications (e.g., venous congestion, arterial insufficiency, or partial flap loss). Only one case (case 4) showed maceration of 

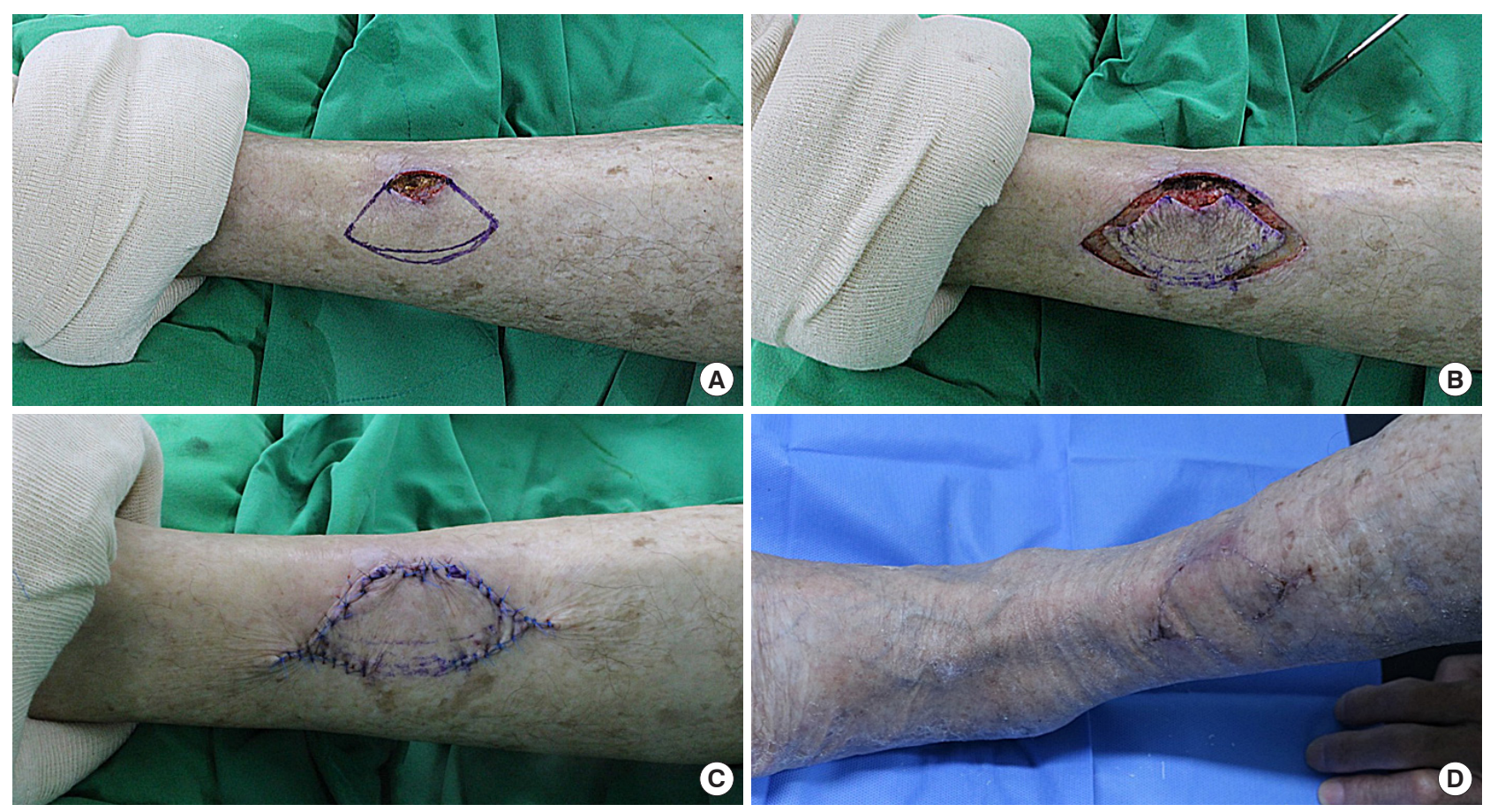

Fig. 2. A 70-year-old man (case 1). (A) The final post-debridement defect $(1.8 \times 4 \mathrm{~cm})$ was at the lower third of the anterior lower leg, and a $3.5 \times 7.5-\mathrm{cm}$ keystone flap was designed on the lateral side of the defect. $(B, C)$ The defect was successfully covered with the Sydney melanoma unit modification keystone flap. (D) Postoperative clinical photograph after 2 months.

part of the flap margin; it was not a fully broken wound, but healed incompletely with partial wound dehiscence at the time the stitches were removed. The maceration was mitigated with conservative dressing and did not require further surgery. There was no development of other postoperative complications such as hematoma, seroma, or wound infection. After an average follow-up period of $4.83 \pm 1.17$ months (range, 4-7 months), no recurrences or problems exist at the operative sites. Furthermore, all patient outcomes were satisfactory.

\section{Case presentations}

Case 1

A 70-year-old man suffered from skin necrosis on the lower third of the left anterior lower leg (Fig. 2). Wound preparation procedures, including serial debridement, conventional wound dressings, and empirical antibiotic medication, were performed for one week. The final post-debridement defect size was $1.8 \times 4 \mathrm{~cm}$. The defect was covered with SMUM KF $(3.5 \times 7.5 \mathrm{~cm})$ from the defect's lateral side. The flap remained completely viable without any postoperative complications. The patient showed favorable outcomes and was satisfied with the result at 5 months follow-up.

\section{Case 3}

A 28-year-old woman suffered from skin necrosis on the lower third of the right anterior lower leg (Fig. 3). Wound preparation procedures, including serial debridement, negative-pressure wound therapy, and empirical antibiotic medication, were performed for one week. The final post-debridement defect size was $1.8 \times 3.5 \mathrm{~cm}$. The defect was covered with an $\mathrm{OV}$ and SMUM KF $(3.5 \times 8 \mathrm{~cm})$ from the lateral side of the defect. The flap was completely viable without any complications. The patient showed favorable outcomes and was satisfied with the result at 7 months follow-up.

\section{Case 5}

A 14-year-old male teenager suffered from a skin avulsion on the upper third of the left anterior lower leg (Fig. 4). Wound preparation procedures, including serial debridement, conventional wound dressings, and intravenous antibiotic therapy, were performed for two weeks. The final post-debridement defect size was $3 \times 4 \mathrm{~cm}$. The defect was covered with an $\mathrm{OV}$ and SMUM KF $(5 \times 12 \mathrm{~cm})$ from the lateral side. The flap was completely viable without any postoperative complications. The patient had a favorable functional outcome without limitations to knee joint motion. However, at 5 months follow-up, there 

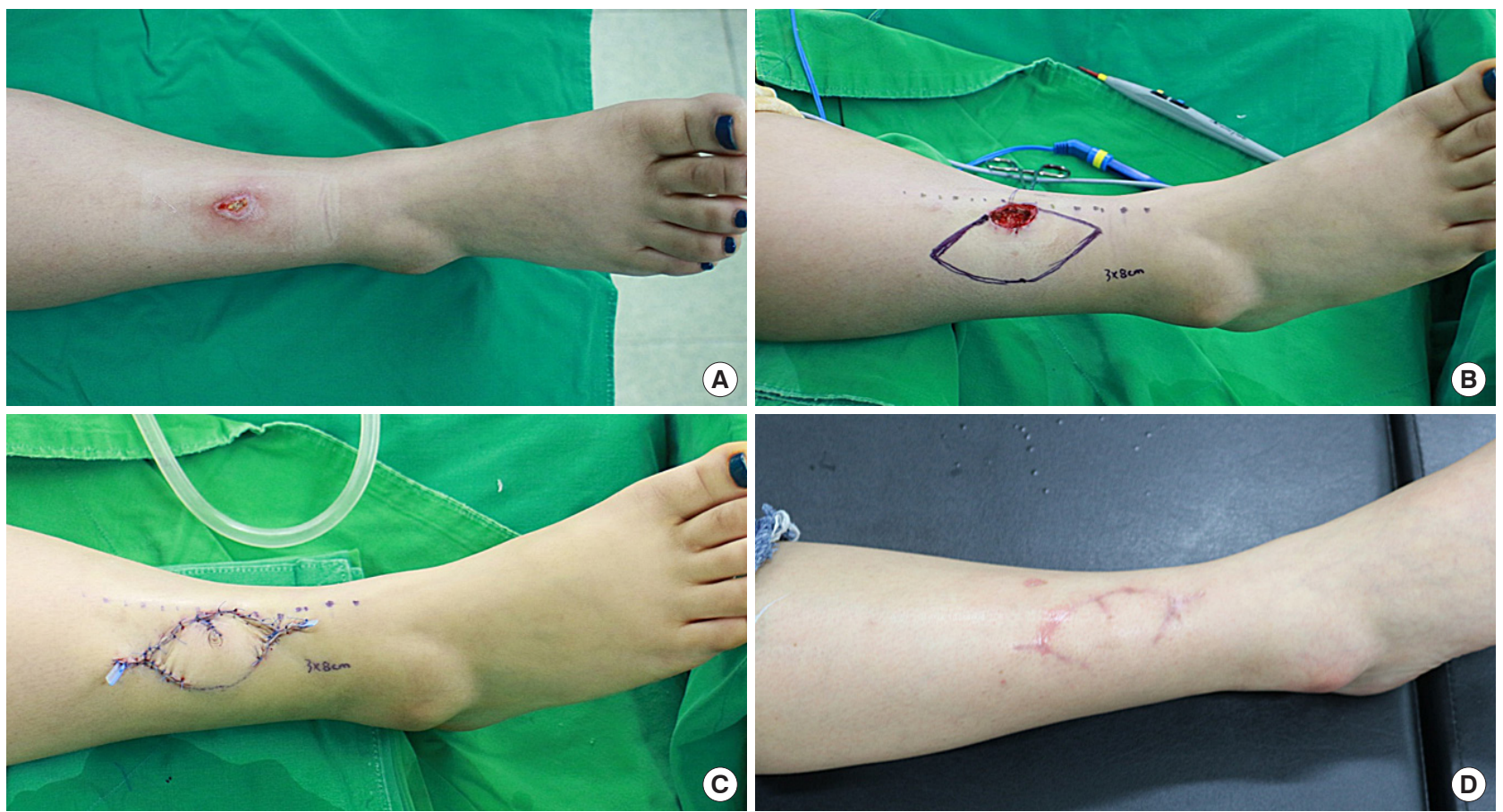

Fig. 3. A 28-year-old woman (case 3). (A) The lesion was located on the lower third of the anterior lower leg. (B) The final post-debridement defect was measured to be $1.8 \times 3.5 \mathrm{~cm}$, and a $3.5 \times 8-\mathrm{cm}$ keystone flap was designed on the lateral side of the defect. (C) The defect was successfully covered with the omega variation and Sydney melanoma unit modification keystone flap. (D) Postoperative clinical photograph after 7 months.


Fig. 4. A 14-year-old male teenager (case 5). (A) The final post-debridement defect $(3 \times 4 \mathrm{~cm})$ was located on the upper third of the anterior lower leg, and a $5 \times 12-\mathrm{cm}$ keystone flap was designed on the lateral side of the defect. (B, C) The defect was successfully covered with the omega variation and Sydney melanoma unit modification keystone flap. (D) Postoperative clinical photograph after 5 months. 
was mild hypertrophic scar formation, even though the patient had used CICA-CARE for postoperative scar management.

\section{Discussion}

The present study described the experience of successfully utilizing the OV and SMUM KF technique to reconstruct six consecutive cases of anterior lower leg defects, conducted by a single surgeon (the corresponding author of this study). As previously stated, reconstruction of anterior lower leg defects is always troublesome and challenging [1,2]. This is particularly true because the anterior lower leg includes pretibial regions, which are nearly bone-to-skin, lack underlying tissues, and have limited tissue mobility $[1,2]$. Therefore, local flap reconstruction is limited, and great care should be taken to apply local flaps in the anterior lower leg [2]. Large anterior lower leg defects may inevitably require free-flap coverage. In contrast, local flap techniques can be a good alternative modality for small- to moderate-sized defects in the anterior lower leg [2]. The present study successfully covered anterior lower leg defects of up to $6 \times 8 \mathrm{~cm}$ in size with OV and SMUM KF technique. Meanwhile, a skin graft is a feasible reconstructive option for anterior lower leg defects exhibiting a healthy granulated wound bed without exposure of underlying structures. However, it has definite disadvantages including other donorsite morbidity, secondary contracture, color mismatch, and contour deformity. The disadvantages prevented the clinicians from considering skin grafts for the majority of the cases in this study.

Though conventional muscle-based local flaps (e.g., soleus, gastrocnemius, and tibialis anterior muscle flaps) have been used for anterior lower leg defects [2], they are usually accompanied by functional deficits, marked donor-site morbidities, or poor aesthetic outcomes [2]. More recently, pedicled perforator flaps (PPFs), in the form of propeller and island flaps, have changed the paradigm of lower limb reconstruction in terms of liberty and flexibility of flap design, decreased donorsite morbidity, and provision of like-with-like tissue type $[2,5,10]$. Several previous studies have demonstrated the PPF reconstruction of lower extremity defects $[2,10]$. PPFs (e.g., peroneal artery, medial sural artery, and posterior tibial artery perforator flaps) are known to cover $75 \%$ of the lower extremity's total surface area from the superior patella to the forefoot [10]. Literature also reports that each flap could cover defects around the lower leg, ranging from $15 \%$ to $26 \%$ of the surface area [10]. Moreover, PPFs are easier to perform and entail less risk than free-flaps as they do not require microsurgical anastomosis $[2,5,10]$. Nevertheless, microsurgical abilities such as the perforator dissection technique and venous supercharging technique are still critical in PPF reconstruction $[2,5,10]$. For residents or novice reconstructive surgeons who lack training in these techniques, simpler flap techniques (e.g., perforatorbased island flap devised by Kim et al. [11] and KF) are a useful alternative $[2,5,6]$ because they do not require microsurgical perforator dissection $[2,12]$. Furthermore, no microsurgical skills were used in any of our cases.

The KF is one type of perforator-based flap devised by Behan in 2003 [9]. It is a multiple perforator-based advancement flap with a curvilinear trapezoidal shape, designed to mimic the keystone in Roman arches [9]. Moreover, KF has gained popularity over the last 20 years as a meaningful innovation in reconstructive surgery and has been applicable as either a primary or an alternative reconstructive method $[2,5,6]$. A variety of studies have described the utility of KF reconstruction to cover diverse defects in almost every part of the body $[2,5,6,13]$. KF has also been used in lower limb reconstruction, mainly after skin and soft tissue tumor resection in the thigh and calf regions $[2,14]$. The vast majority of previous studies demonstrated KF reconstruction in the lateral and posterior lower extremities, which typically have sufficient tissue volume for recruitment. However, only a few studies have applied the KF for anterior lower extremity reconstruction [2]. A previous study conducted by the present study's senior author group demonstrated a successful case series of traumatic pretibial defect reconstruction using KF [2]. It emphasized that while KF may not be the primary flap of choice for covering pretibial defects, it can still be a good alternative to other reconstructive options in selected cases [2]. The present study, an extension of the previous study, focuses on the effectiveness of OV and SMUM KF for covering small- to moderate-sized defects in the anterior lower leg.

The KF consists of double-opposing V-Y flaps joined together; their advancement toward the flap center (along the longitudinal axis) provides some residual laxity within the flap, which allows for KF movement into the defect (along the horizontal axis) $[2,5,6]$. Fundamentally, the gradual release of tissue layers, including skin (especially dermis), superficial fascia (subcutaneous layer), and deep fascia during flap dissection promotes KF movement $[6,15]$. Additionally, minimal undermining of the flap margin provides additional flap movement $[2,5,6,13,15]$. Particularly, these biomechanics form the basis of the KF movement and result in the principal 
recruitment of tissue laxity in $\mathrm{KF}$ reconstruction $[5,6,15]$. Namely, KF reduces wound tension through recruitment and rearrangement of tissue laxity $[5,6,15]$. Securing minimal wound tension when covering defects is crucial because there is insufficient surrounding tissue in the anterior lower leg [5]. Attempts for classical KFs without any modifications may encounter difficulties covering the anterior lower leg defects due to the aforementioned inherent feature.

From these perspectives, both OV and SMUM are very useful modifications in the KF reconstruction of the anterior lower leg. OV KF provides further flap movement via additional rotational movement, further reducing tension without sacrificing the healthy tissues in wound closure [2,6,7]. Meanwhile, SMUM KF allows additional vascularity and provides structural stabilization of the flap by maintaining a skin bridge along the greater arch of the KF $[2,6,8]$. The KFs' complete viability, with no flap-related complications, was achieved in the present study by applying OV and SMUM in all cases. Also, there were no significant complications, and all patients experienced favorable outcomes. Meanwhile, the present study did not establish a specific range for the size of the defect to qualify for KF reconstruction. The smallest defect among the current study cases was $1.5 \times 2.5 \mathrm{~cm}$, which could be considered adequate to achieve primary closure with undermining or bilateral skin flap advancement [15]. However, as each patient has different skin properties, some small defects may achieve ineffective primary closure when there is a certain level of wound tension and persistent dead space, possibly causing obstacles to the wound healing [15]. The skin properties of each patient and characteristics of surrounding tissues should be considered when determining the effectiveness of flap reconstruction for covering defects [15]. Furthermore, KF reconstruction was performed in all cases in the present study because the authors believed that it would be effective in minimizing wound tension in the anterior lower leg, which would facilitate the postoperative wound healing process with minimal complications.

This study has some limitations despite its successful results. First, the present study is a nonrandomized retrospective clinical review with very small sample size and no comparison group $[2,5,13]$, meaning that some selection bias and confounding factors inevitably exist. Further prospective largescale studies are required to confirm consistently favorable outcomes $[2,5,13]$. Second, OV and SMUM KFs cannot be the only solution for anterior lower leg defects as other local flap techniques can also achieve good results, depending on the specific conditions of each wound. It is important that sur- geons determine the best method to ensure the most favorable outcome for each case [6]. Third, compared to linear scars in primary closure with undermining, KF reconstruction inevitably extends operation scars $[6,15]$. Furthermore, the KF presents a larger flap size with longer incisions than other conventional local flaps (e.g., the Limberg, rotation, and transposition flaps) [6,15]. Additionally, dog-ear deformity in both ends of the KF and cone deformity in the OV KF can occur, which results in less aesthetically pleasing outcomes [6]. Therefore, surgeons should explain thoroughly the possibility of extended scar formation to patients undergoing KF reconstruction and stress the necessity for longer postoperative scar management $[6,15]$.

This study successfully covered small- and moderate-sized anterior lower leg defects with OV and SMUM KF with favorable outcomes. Based on the present study experience, the OV and SMUM KF techniques are considered good alternative modalities for anterior lower leg reconstruction.

\section{Conflict of interest}

No potential conflict of interest relevant to this article was reported.

\section{ORCID iDs}

Yu Taek Kong https://orcid.org/0000-0001-6267-4463

Junekyu Kim https://orcid.org/0000-0002-8904-5605

Hyun Woo Shin https://orcid.org/0000-0003-4396-3395

Kyu Nam Kim https://orcid.org/0000-0001-9998-8722

\section{References}

1. Shin IS, Lee DW, Rah DK, et al. Reconstruction of pretibial defect using pedicled perforator flaps. Arch Plast Surg 2012;39:360-6.

2. Yoon CS, Kim SI, Kim H, et al. Keystone-designed perforator island flaps for the coverage of traumatic pretibial defects in patients with comorbidities. Int J Low Extrem Wounds 2017;16:302-9.

3. Hong JP. The use of supermicrosurgery in lower extremity reconstruction: the next step in evolution. Plast Reconstr Surg 2009;123:230-5.

4. Yoon CS, Kim KN. Selective salvage of zones 2 and 4 in the pedicled TRAM flap: a focus on reducing fat necrosis and improving aesthetic outcomes. Springerplus 2016;5:68. 
5. Lee HG, Lim SY, Kim YG, et al. Keystone design perforator island flaps for coverage of non-oncological periarticular defects surrounded by the zone of injury. J Int Med Res 2020;48:1-14.

6. Lim SY, Yoon CS, Lee HG, et al. Keystone design perforator island flap in facial defect reconstruction. World J Clin Cases 2020;8:1832-47.

7. Behan FC, Rozen WM, Lo CH, et al. The omega - $\Omega$ - variant designs (types $\mathrm{A}$ and $\mathrm{B}$ ) of the keystone perforator island flap. ANZ J Surg 2011;81:650-2.

8. Moncrieff MD, Bowen F, Thompson JF, et al. Keystone flap reconstruction of primary melanoma excision defects of the leg-the end of the skin graft? Ann Surg Oncol 2008;15: 2867-73.

9. Behan FC. The keystone design perforator island flap in reconstructive surgery. ANZ J Surg 2003;73:112-20.

10. Wong JK, Deek N, Hsu CC, et al. Versatility and "flap efficiency" of pedicled perforator flaps in lower extremity reconstruction. J Plast Reconstr Aesthet Surg 2017;70:67-77.
11. Kim JT, Kim YH, Naidu S. Perfecting the design of the gluteus maximus perforator-based island flap for coverage of buttock defects. Plast Reconstr Surg 2010;125:1744-51.

12. Yoon CS, Kim CG, Kim H, et al. Retrospective study of freestyle perforator-based peninsular flaps: a simple, fast, and safe technique for pressure sore reconstruction. Medicine (Baltimore) 2018;97:e0168.

13. Yoon CS, Kim HB, Kim YK, et al. Relaxed skin tension line-oriented keystone-designed perforator island flaps considering the facial aesthetic unit concept for the coverage of small to moderate facial defects. Medicine (Baltimore) 2019;98:e14167.

14. Khouri JS, Egeland BM, Daily SD, et al. The keystone island flap: use in large defects of the trunk and extremities in soft-tissue reconstruction. Plast Reconstr Surg 2011;127: 1212-21.

15. Yoon CS, Kim HB, Kim YK, et al. Keystone-design perforator island flaps for the management of complicated epidermoid cysts on the back. Sci Rep 2019;9:14699. 